population in spite of the rather small and heterogenous material examined we find that the trends are parallel to those seen elsewhere indicating the global nature of the current herpes pandemic. The fact that most other STDs especially the bacterial ones are treated at the primary level by virtue of the large number of currently available antibiotics, all easily available over the counter, herpes is likely to remain a major public health problem. Geographic and socioeconomic influences as stated by Guinan et $\mathrm{al}^{4}$ do not seem to play such a role in our population. Asymptomatic infection plays a major role in maintaining viral circulation in society, while the sexual activity, age at first intercourse and type of contraceptives used may influence the risk of acquisition. These factors have to be borne in mind when developing an effective control programme. At present there is no such programme on a national scale for herpes but judging from the trends projected, it may very soon become a necessity.

BHUSHAN KUMAR M RAJAGOPALAN The Department of Dermatology, Postgraduate Institute of Medical Education and Research, Chandigarh, India 160012

1 Simonsen JN, Cameron DW, Gakinya $\mathrm{MN}$, et al. Human immunodeficiency virus infection among men with sexually transmitted diseases. Experience from a center in Africa. N Engl J Med 1988;319:274-8.

2 Adler MW. Epidemiology of STDs in the west. Sem Dermatol 1990;9:96-101.

3 Thirumoorthy T. The epidemiology of STDs in Southeast asia and the Western pacific. Sem Dermatol 1990;9:102-4.

4 Guinan ME, Wolinsky JM, Reichman RC. Epidemiology of genital herpes simplex virus infection. Epidemiol Rev 1985; 7:127-46.

\section{Screening for Chlamydia trachomatis in a Turkish population}

In the last few years Chlamydia trachomatis has been recognised as one of the most important sexually transmitted pathogens. Genital infections due to this organism present a major world-wide public health problem.

We evaluated 93 out of 100 endocervical specimens obtained from nonpregnant women in their first visit to the gynaecology out-patient clinic in the Ege University Hospital, irrespective of their reason for attendance. The patient group consisted of both symptomatic and asymptomatic patients. The patients were grouped according to their ages, subjective symptoms and cervical lesions. Specimens were tested by a commercially available direct immunofluorescence test kit (Chlamyset, Orion Diagnostica, Finland). Specimens were considered positive if ten or more fluorescing elementary bodies were seen. The overall positivity rate was $34.4 \%$ (32/ 93). The results are shown in the table.
Table The rates of genital chlamydial infection in different patient groups

\begin{tabular}{|c|c|c|c|}
\hline \multirow[b]{2}{*}{ Groups } & \multirow{2}{*}{$\begin{array}{l}\text { Number } \\
\text { of } \\
\text { patients }\end{array}$} & \multicolumn{2}{|c|}{$D F A$ positive } \\
\hline & & Number & $\%$ \\
\hline $\begin{array}{l}\text { Age (years) } \\
<30 \\
30-40 \\
>40\end{array}$ & $\begin{array}{l}34 \\
48 \\
11\end{array}$ & $\begin{array}{r}9 \\
19 \\
4\end{array}$ & $\begin{array}{l}26 \cdot 5 \\
39 \cdot 6 \\
36 \cdot 4\end{array}$ \\
\hline $\begin{array}{l}\text { Symptoms and signs } \\
\text { Group I* } \\
\text { Group II } \dagger \\
\text { Group III } \ddagger\end{array}$ & $\begin{array}{l}37 \\
45 \\
11\end{array}$ & $\begin{array}{r}12 \\
17 \\
3\end{array}$ & $\begin{array}{l}32 \cdot 4 \\
37 \cdot 8 \\
27 \cdot 3\end{array}$ \\
\hline Total & 93 & 32 & $34 \cdot 4$ \\
\hline
\end{tabular}

«Patients with only subjective symptoms.

†Patients with subjective symptoms plus cervical lesions. $¥$ †symptomatic patients.

Tissue culture is considered as the "gold standard" in the diagnosis of chlamydial infections. ${ }^{1}$ Since tissue culture techniques are not practical for most clinical laboratories, non-culture antigen detection tests have become available and widely used. Direct fluorescent antibody (DFA) is one of these tests and its advantages over tissue culture are that it does not require a transport system, can detect both dead and live organisms, makes it possible to assess the specimen adequacy, is less expensive, and the results are available days earlier. ${ }^{12}$ The sensitivity and specificity of the DFA test are in the range of 50$96 \%$, and $94-96 \%$ respectively. Therefore, it is recommended as an alternative to the tissue culture in high risk populations. ${ }^{13}$

In this study we used the DFA test for screening, since our laboratory facilities were very limited for tissue culture.

The overall infection rate was $34 \cdot 4 \%$ in our study. Similar percentages have been reported in previous studies using similar techniques. ${ }^{14}$ Our highest positivity rate was found in the $30-40$ age group $(39.6 \%)$. Although chlamydial infections are known as the most prevalent venereal disease in adolescents and young women at child bearing age, ${ }^{5}$ this is not true for the Turkish female population, because sexual activity usually begins with marriage and the marriage age has risen $(>25)$ in the past few years, especially in the cities. Although genital chlamydial infections are reported to be associated with clinical signs and symptoms, they may also show an asymptomatic course. In some studies, the positivity rates in symptomatic women were found to be significantly higher than the control groups. ${ }^{5}$ In contrast, there have also been studies in which no significant difference between symptomatic and asymptomatic women has been found. ${ }^{16}$ In our study, there was no statistically significant difference between the positivity rates of the three patient groups shown in the table. Although the number of patients in the 
groups was small, our results were similar to those of some previous studies mentioned above.

In conclusion, the results of our study have shown that genital chlamydial infections are highly prevalent in our region. Therefore, further studies on both the prevalence of these infections and comparison of different diagnostic tests are needed in our country.

We are grateful to Ahmet Hüdaverdi and Ali Köse for their technical help. We also thank the staff of the Gynecology out-patient clinic for providing the patients.

EKIN ERTEM

DENIZ DEREL

DEMIR SERTER KEMAL YUCE

Ege University Medical Faculty, Clinical Bacteriology and Infectious Diseases Department, Bornova, Izmir, Turkey
1 Quinn TC, Warfield P, Kappus E, Barbacci M, Spence M Screening for Chlamydia trachomatis infection in an inner-city population: a comparison of diagnostic methods. J Infect Dis 1985;152:419-23.

2 Lipkin ES, Moncada JV, Shafer MA, Wilson TE, Schachter J. Comparison of monoclonal antibody staining and culture in diagnosing cervical chlamydial infections. J Clin Microbiol 1984;23:114-7.

3 Phillips RS, Hanff PA, Kaufman RS, Aronson MD. Use of a direct fluorescent antibody test for detecting Chlamydia trachomatis cervical infection in women seeking routine gynecologic care. J Infect Dis 1987;156:575-81.

4 Tilton RC, Judson FN, Barnes RC, Gruninger RP, Ryan RW, Steingrumsson $\mathrm{O}$. Multicenter comparative evaluation of two rapid microscopic methods and culture for detection of Chlamydia trachomatis in patient specimens. J Clin Microbiol 1988;26:167-70.

5 Chacko MR, Louchik JC. Chlamydia trachomatis infection in sexually active adolescents: Prevalence and risk factors. Pediatrics 1984;73:836-40.

6 Rahm V-A, Gnarpe H, Odlind V. Chlamydia trachomatis among sexually active teenage girls: lack of correlation between chlaymdial infection, history of the patient and clinical signs of infection. Br J Obstet Gynaecol 1988;95:916-9.

Accepted for publication 28 March 1991 